Historic, Archive Document

Do not assume content reflects current scientific knowledge, policies, or practices. 


\section{The Animal Welfare Act}

How It Protects Your Dog and Cat

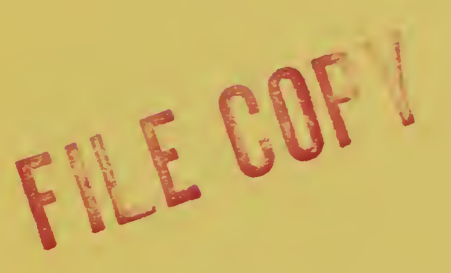


If you own a dog or cat, or are in the market for one, you may want to know about the Animal Welfare Act-a Federal law that requires humane care, treatment, and transportation for your pet and other animals.

- The law requires wholesale animal breeders and dealers to handle dogs and cats humanely.

- The law requires animal dealers to keep records that help trace lost and stolen dogs and cats.

- The law requires humane handling of dogs and cats traveling on commercial vehicles.

- The law requires humane treatment of dogs and cats in laboratories, exhibitions, or in commercial resale businesses.

\section{The Animal Welfare Act}

Congress passed the Act in 1966, and later amended it in 1970 and 1976. It protects not only dogs and cats, but also many other animals. Principally, the Act covers animals if used for research studies in laboratories, if exhibited in zoos and circuses, if raised for sale to pet shops, and if transported commercially. At present, the Act does not cover birds, rats, mice, domestic farm livestock, and coldblooded animals, like snakes and alligators.

In passing the Act, Congress moved to correct abuses in the commercial handling of many warmblooded animals, especially dogs and cats. Testimony in Congressional hearings showed that dogs and cats used in laboratory work sometimes suffered unnecessarily.

Sometimes dogs and cats were commercially produced for the pet market without proper care and treatment. And dogs and cats shipped in commerce sometimes got no more attention than a load of machine parts.

Enforcement of the Act is carried out by the U.S. Department of Agriculture (USDA), principally through its Animal and Plant Health Inspection Service (APHIS). This agency licenses or registers dog and cat breeders, dealers, brokers, transportation companies, exhibitors, and research facilities. However, most retail pet stores and private individuals who sell dogs and cats as pets to individual owners are not regulated. 


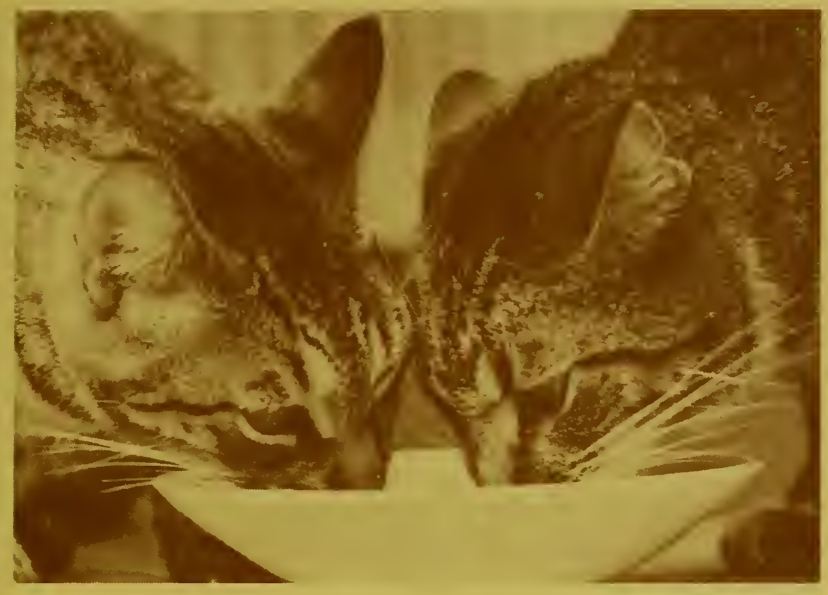

Regulated businesses must identify each dog and cat they handle and keep records on the origin and disposition of each animal. These businesses also must follow Federal standards for humane care and treatment of dogs and cats. These include: housing, handling, feeding, watering, sanitation, ventilation, transportation, and protection against extremes of heat, cold, and weather. Animals also must receive proper veterinary care, and incompatible animals must be separated from one another.

APHIS veterinarians and animal health technicians enforce these regulations and standards by regular inspections of licensed and registered persons, and animal care compliance officers conduct thorough investigations of violations. Persons convicted of violations can be penalized by suspension or revocation of their license to do business - plus they can receive fines, or even prison sentences for serious offenses.

\section{Production and Shipment of Puppies and Kittens}

Dog and cat breeders for the pet trade must be licensed by APHIS and inspected to assure that they comply with Federal standards for animal care and treatment.

When breeders ship puppies or kittens to market, the young animals must be at least 8 weeks old. The only exception is for puppies and kittens shipped to research institutions. Then the young animals must be weaned or be transported with their mother.

Dogs and cats must be examined by a licensed veterinarian within 10 days of the time they are shipped, and a health certificate must 
be prepared showing that they are healthy. You may want to see this health certificate when you buy an animal. However, to be sure of your new pet's current health, APHIS suggests you have your own veterinarian give the dog or cat a health check right after purchase. Anyone taking custody of your future pet as it travels to the pet store comes under Federal regulation. This includes brokers who make up shipments and truckers who move puppies and kittens to freight terminals.

The Animal Welfare Act places a special responsibility on commercial carriers-airlines, trains, and trucks that carry dogs and cats. The carrier's agent must see to it that the animal being shipped is not too young, has a valid health certificate, and travels in a safe, strong container with adequate space and ventilation. If a pet shipment is delayed, carriers must provide shelter, food, and water. In transit, pets must be protected from excessively high or low temperatures and must receive adequate ventilation. After animals arrive at a terminal, the carrier must notify the pet store to pick up the shipment promptly or arrange to give the animals proper care until they are called for.

\section{Traveling with Your Dog or Cat}

The Animal Welfare Act again provides protection for your pet if you take it with you on a trip by commercial carrier or ship it alone.

Both you and the carrier must meet certain requirements that assure the safety and health of your pet throughout the trip.

You, as shipper of the animal, must not ship dogs or cats if they are less than 8 weeks old. You must provide a sturdy, comfortable, well-

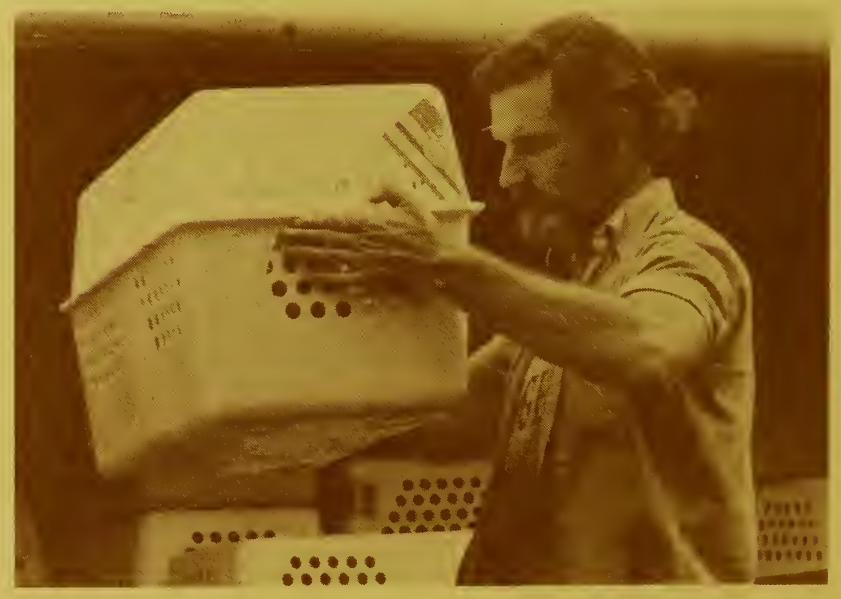




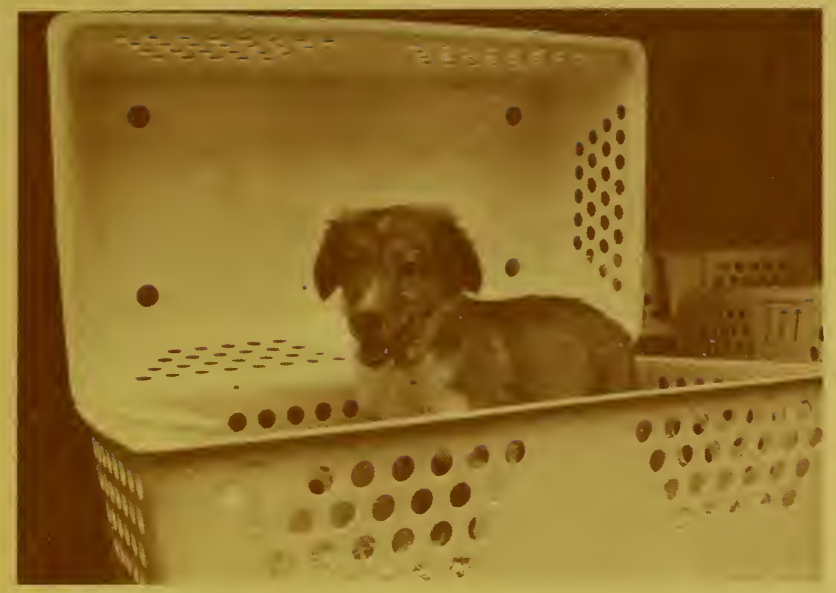

ventilated container that meets Federal standards. You should call the carrier well ahead of time to get a reservation for your pet; and you must make special arrangements with the carrier to hold your pet safely at the terminal if you drop it off more than 4 hours before the scheduled departure. You may not drop off your pet more than 6 hours before departure. Identification of the animal and its destination must be clearly marked on the container; and if the trip is to be an unusually long one, you must provide instructions for food and water.

Although Federal law does not require you, as a pet owner, to obtain a veterinary health certificate to ship your pet, it is a good idea to have your veterinarian examine your dog or cat and fill out a certificate. Most States require health certificates for dogs and cats shipped in from outside the State. And the carrier may ask you for a certificate rather than attempt to distinguish between your personal pet and a commercially shipped animal, for which a Federal health certificate is required.

After accepting your pet, a carrier must give it the same care, traveling conditions, and prompt handling required for all traveling dogs and cats. You yourself should make arrangements to have your pet picked up promptly after arrival, or else the carrier may have to board your pet-at your expense.

\section{Protection for Strayed or Stolen Pets}

Some thieves cruise a neighborhood and "petnap" dogs and cats for later sale as hunting dogs, guard dogs, pets, or laboratory animals. Of course, reputable dealers and research facilities do not want stolen or strayed pets; however, before passage of the 
Animal Welfare Act, it was difficult for buyers to check the source of the dogs and cats they purchased.

The Act requires every federally licensed or registered business, institution, or agency to record the name and address of every person from whom it buys a dog or a cat. Each animal must be identified individually, and the records must show the identifying number and description. Whenever a dealer acquires a dog or cat, the animal must be held for a specified time to facilitate the tracing of lost or stolen animals.

Federal inspectors check the accuracy of records by comparing them with the records kept by other dealers in the same marketing chain. While this recordkeeping system does not prevent all "petnapping," it discourages thieves from selling stolen pets through commercial market channels.

USDA officials have the following suggestions on what you as a pet owner can do to protect your dog or cat from loss or theft:

1. Provide identification. Immediately take steps to individually identify your dog or cat. Tattoos are best because they can't get lost and are difficult to alter. Tags on the collar have the advantage of providing space for clearer, more detailed information. There is nothing wrong with having both tattoos and tags. Also, jot down for later reference your pet's identifying marks, plus its color, breed, and size, and take a clear, closeup color photograph.

2. Restrain pets. Keep cats inside. Put dogs outside only in fenced yards or on a leash. Train dogs to return to your side on verbal command. Keep dogs and cats from roaming by neutering them at the age your veterinarian recommends-usually about 6 months.

3. Know your allies. Prepare a list of persons who can help you find a lost or stolen pet, and keep the list handy and up to date. List the phone numbers of local pounds, shelters, and other animal collection centers. Add newspaper offices, radio stations, and TV stations that have lost-and-found departments, as well as police, sheriff, dog warden, and other officials who might help.

4. Act promptly. The quicker you start looking for a lost dog or cat, the better. Tracing becomes more difficult as people's memories dim. Search your own neighborhood frequently; 


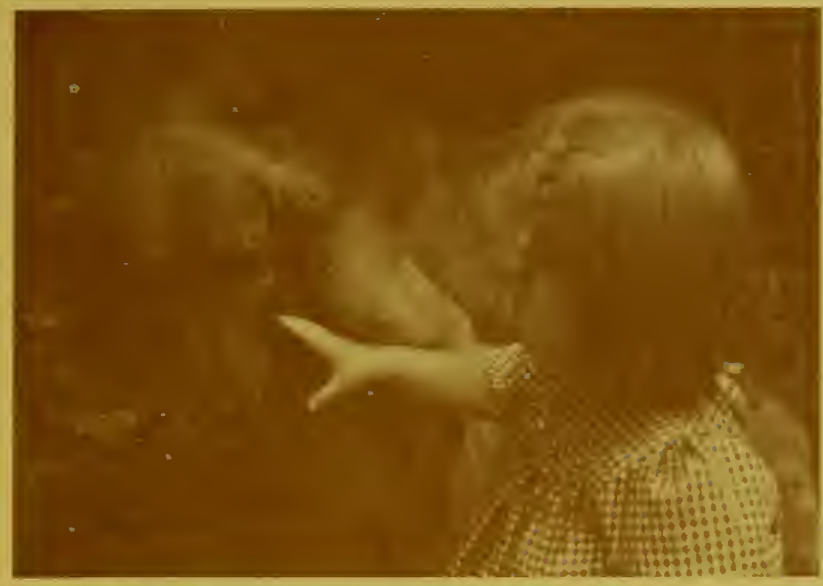

then widen your search, calling the "allies" on your list. Spread the identification of your pet and its photograph to bulletin boards and to everyone you ask about your pet.

Don't overlook children in the neighborhood as a source of information; they seem to have an eye open for pets out of place.

5. Don't give up. Keep looking for more than a few days. Strays sometimes return to their old neighborhood days or even weeks after you first miss them.

\section{Protecting Animals in Research}

Dogs and cats are used as laboratory animals in some experiments to improve human health and well-being. Many of these animals are specifically bred for the purpose; the rest are surplus dogs and cats brought to pounds.

Laboratory animal dealers and institutions using laboratory animals are regulated by APHIS and must comply with the Federal standards for the care and treatment of dogs, cats, and other animals. At research institutions, a veterinarian must certify that acceptable standards of care and treatment are provided for the animals. Dealers and research institutions are inspected periodically for compliance.

\section{Other Protection for Dogs and Cats}

Handlers of dogs and cats working in animal acts, such as those seen in circuses, also are licensed or registered by APHIS. In addition to meeting Federal standards of care, regulated exhibitors must see to it that animals are not cruelly trained or overworked.

Another provision of the Animai Welfare Act prohibits dogfighting exhibitions. USDA co- 
operates with Federal, State, and local law enforcement agencies to track down those involved. The Act provides for large fines and heavy prison sentences for those convicted of engaging in or promoting dogfights.

\section{Unwanted Pets Pose Problems}

Pet ownership is fun, but it also is a responsibility. Millions of people who have dogs and cats sometimes forget this. As a result, animal shelters destroy a surplus population of nearly 13 million dogs and cats each year; another 5 million are abandoned and roam wild. Most die within a year-they starve, die from disease, or are struck by vehicles. While they run loose, however, they may spread disease and bite or scratch the unwary.

So think ahead and avoid having unwanted pets on your hands. Don't get a pet unless your family can take care of it. Be sure a specific member of your family is responsible for it. Choose a type and breed of dog or cat that suits your needs now and in the future-and one that is suitable for your home or apartment. And get your dog or cat neutered after it is 6 months old, so it won't produce unwanted young. Only those seriously and knowledgeably interested in breeding purebred animals should assume responsibility for raising litters of dogs and cats.

If you no longer can care for a pet, try to find it another home with people who will care for it properly. If that is impossible, don't just abandon the animal to a random death. The most humane alternative is to have a veterinarian end its life painlessly.

USDA welcomes the cooperation of informed people in enforcing the Animal Welfare Act. Complaints from the public receive first priority for inspection. Anyone who knows of an apparent violation of the Act should write the Animal Care Staff, Animal and Plant Health Inspection Service, USDA, Room 703 Federal Building, 6505 Belcrest Road, Hyattsville, MD 20782. 